\title{
An investigation into polymer flooding in high temperature and high salinity oil reservoir using acrylamide based cationic co-polymer: experimental and numerical simulation
}

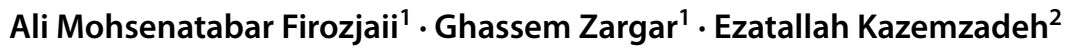

Received: 25 August 2018 / Accepted: 5 October 2018 / Published online: 12 October 2018

(c) The Author(s) 2018

\begin{abstract}
In this study, the new type of polymer was considered for rheological study and core flooding test in high temperature and high salinity (HTHS) condition. This polymer is called co-polymer Zetag $8187 \mathrm{G}$ which is used as flocculant in water industry. By studding the rheological properties of this polymer compared to one of the commercial polymer for HTHS condition, Zetag $8187 \mathrm{G}$ was considered for polymer flooding in sandstone core at $185^{\circ} \mathrm{F}$ and $150,000 \mathrm{ppm}$ of salinity in present of divalent ions $\left(\mathrm{Ca}^{2+}, \mathrm{Mg}^{2+}\right)$ in experimental and simulation cases due to better stability compared to other. The core flooding results showed this co-polymer swept the oil toward low residual oil saturation in porous media. In addition, the core flooding results showed that was not occurred significant damage in rock during polymer flooding using Zetag 8187G. More than, in the simulation case, the change of relative permeability curve during water and polymer flooding was obtained using history matching of production data. The experimental and simulation results show this polymer can applicable in oil industry as well as application in water industry.
\end{abstract}

Keywords Polymer flooding $\cdot$ High temperature $\cdot$ High salinity $\cdot$ Cationic Co-polymer $\cdot$ Experimental $\cdot$ Numerical simulation

\section{Introduction}

World energy demand is increasing as the developed and developing of the industry. Today, fossil fuels, especially oil and gas, play a major role in providing energy. Thus, to encounter the world energy demand, it is necessary to increase the oil reserves and capability of oil production (Lyons and Plisga 2011). When the reservoir pressure is not enough for assisting the production, external fluid such as water or gas is injected to prevent of decreasing in production by increasing the reservoir pressure. More than, enhanced oil recovery (EOR) methods can be helpful to increase oil recovery (Sandrea and Sandrea 2007). EOR process strongly depends on economic condition and oil fee.

Ali Mohsenatabar Firozjaii

ali_mohsen_tabar@yahoo.com

1 Petroleum University of Technology, Abadan Institute of Technology (AIT), Abadan, Iran

2 Petroleum Engineering Research Division, Research Institute of Petroleum Industry, Tehran, Iran
When oil fee is high the EOR process benefits (Alvarado and Manrique 2010). There is now a tendency in the business that companies again are doing research and development on viscous flooding. Polymer flooding is the first choice for viscous flooding as popular (chemical EOR) CEOR method. Because it is simple to apply and have low cost (Wang et al. 2003). In this method, water soluble Polymer will be added to the injection water to increase the viscosity of solution which provides mobility control between water and oil and increases sweep efficiency (Pope 1980). Polymer flooding can yield a significant increase in oil recovery compared to conventional water flooding because of piston-like sweeping (Abidin et al. 2012).

Degradation of polymer solution during field operation is a major problem. It can be chemical degradation through oxidation or the effect of ions and temperature. In high temperature and high salinity conditional thermal degradation of the commercial polymers such as hydrolyzed polyacrylamide (HPAM) lose its viscosity because of its low tolerance to such condition (Vermolen et al. 2011). In high temperature condition HPAM molecule is hydrolyzed and find negative charge. Then, as show in Fig. 1, in the presents of 
Fig. 1 Trapping the acrylamide molecule by divalent ion (Jiang and Zhu 2014)

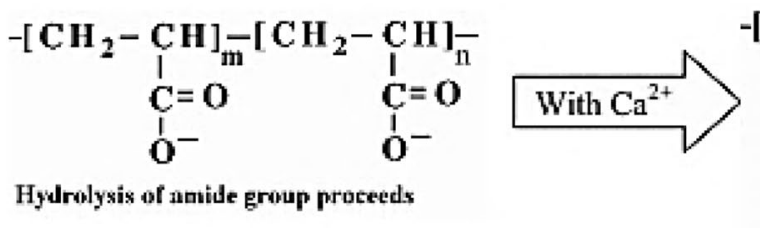

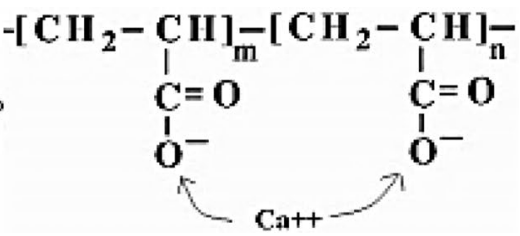

divalent ions (such as $\mathrm{Ca}^{2+}, \mathrm{Mg}^{2+}, \mathrm{Fe}^{2+}$ ), these molecules are trapped. Therefore, formation damage and permeability reduction are made due to polymer molecule trapping.

Today polymer flooding in a reservoir with high temperature and high salt content is an important challenge for this industry (Han et al. 2013). Detecting salt-tolerant and thermally stable, polymers with high efficiency and low adsorption on rock surface is a main step to the success of polymer flooding in HTHS reservoirs (Zhu et al. 2014). To solve this problem, Sulfonated polymers have also been tested by several investigators using core flooding experiments for a temperature up to $100{ }^{\circ} \mathrm{C}$ and the results showed promising oil recovery (Hashmet et al. 2017). Therefore, using modified polymer from HPAM can be stable in HTHS condition (Wu et al. 2012). Today many types of synthetic and biopolymer polymer are designed for polymer flooding in HTHS condition. Wang et al. (2011), developed a new Thermoviscosifying polymers (TVP) mainly based on thermosensitive poly ( $N$-isopropyl acrylamide) (PNIPAM) and polyethylene (PEO). Vermolen et al. (2011), used HPAM base Co- and Ter-polymer functionalize with 2-acrylamido-2-methylpropane sulfonate (AMPS) and $n$-vinyl pyrollidone ( $n$-VP) monomer for polymer flooding in HTHS condition in Middle Eastern carbonate reservoir. The AMPS group provides thermal stability and $n$-VP group provides resistance to salt. Wang et al. (2012), synthesized a new co-polymer appropriate for polymer flooding. This polymer was produced from mixing of hydrophobic monomer $\mathrm{N}$-dodecyl acrylamide, acrylamide, and polar monomer 2-acrylamido-2-methylpropanesulfonic acid via micellar polymerization in water. That co-polymer was stable for 30 days in $85^{\circ} \mathrm{C}$ and $32,000 \mathrm{ppm}$ salinity. Zhu et al. (2014), applied the aqueous hybrids of silica nanoparticles and polyacrylamide for HTHS condition. It showed the addition of silica nanoparticles, increase the apparent viscosity and elastic modulus of HPAM solutions. Quadri et al. (2015), experimented polymer flooding process on carbonate core using the biopolymer schizophyllan. The Schizophyllan is used in Asia as medicinal to strengthen the immune system and in South America, is used as a food supplement. Otherwise, the experimental results showed it has excellent viscosity and high tolerance toward to HTHS condition. Sarsenbekuly et al. (2017) investigated the effect of salt and temperature on the stability of a hydrophobically modified polyacrylamide-based (PAM-based) novel functional polymer (RH-4). Stability of this polymer by increasing salinity and temperature showed it can be used for EOR.
High molecular weight and cationic polymers can be useful in polymer flooding in HTHS condition because of their thermal and mechanical stability. Because by increasing charge in polymer molecule the viscosity of solution is increased. Otherwise, by increasing molecular weight, the viscosity in a polymer concentration is increased compared to low molecular weight of polymer. More than, high molecular weight polymer reduces the polymer concentration and the consequence of polymer flooding costs tends to decrease. Using cationic polymer did not study in world compared to other polymers (Kamal et al. 2015). It seems the synergy of high molecular weight and cationic charge can help the polymer molecule stability in high temperature and high salinity.

In this study, two types of polymer are considered for rheological study. First SAV 37, that is a ter-polymer containing $N$-Vinyl-Pyrollidone that can sustain high temperatures and are efficient even in high salinity brines that is designed for polymer flooding in HTHS condition. But second Zetag $8187 \mathrm{G}$, that is a co-polymer of acrylamide and quaternized cationic monomer is used as flocculant in water industry. By studding the rheological behavior of polymer solution depend on temperature and salinity the best polymer is considered for polymer flooding. The polymer flooding is applied in high temperature $\left(185^{\circ} \mathrm{F}\right)$ and high salinity $\left(150,000 \mathrm{ppm}\right.$ in presents of $\left.\mathrm{Ca}^{2+}, \mathrm{Mg}^{2+}\right)$ in low permeability sandstone. Additionally, numerical simulation study is employed for history matching and then relative permeability curves during water and polymer flooding are obtained.

\section{Experimental producer}

\section{Material}

\section{Reservoir fluid and core samples}

The light oil from Gachsaran oil field of Iran were considered for crude oil. The density and viscosity of the crude oil are summarized in Table 1. Additionally, a block of

Table 1 Crude oil properties at two different temperatures

\begin{tabular}{lll}
\hline Temperature & Density $\left(\mathrm{g} / \mathrm{cm}^{3}\right)$ & Viscosity $(\mathrm{cp})$ \\
\hline $77 \mathrm{~F}$ & 0.8421 & 34.847 \\
$185 \mathrm{~F}$ & 0.8515 & 5.0247 \\
\hline
\end{tabular}


Table 2 Petro-physical properties of the cores

\begin{tabular}{lrr}
\hline & \multicolumn{1}{c}{ AS-1 } & \multicolumn{1}{c}{ AS-1 } \\
\hline Length $(\mathrm{cm})$ & 7.602 & 7.602 \\
Diameter $(\mathrm{cm})$ & 3.686 & 3.687 \\
Pore volume $\left(\mathrm{cm}^{3}\right) @ 14.7 \mathrm{psi}$ & 15.833 & 15.834 \\
Pore volume (cm $\left.{ }^{3}\right) @ 2000 \mathrm{psi}$ & 14.083 & 13.804 \\
Porosity-gas (\%) & 19.040 & 19.061 \\
Porosity-water (\%) & 19.519 & 19.520 \\
Permeability (brine water-mD) & 17.956 & 18.034 \\
\hline
\end{tabular}

Table 3 Properties of formation water

\begin{tabular}{lcc}
\hline Electrolyte & Weight $(\mathrm{g})$ & $\mathrm{Mw}(\mathrm{g} / \mathrm{mol})$ \\
\hline $\mathrm{NaCl}$ & 110 & 58.44 \\
$\mathrm{KCl}$ & 2 & 74.56 \\
$\mathrm{CaCl}_{2}$ & 5 & 110.98 \\
$\mathrm{MgCl}_{2}$ & 33 & 95.22 \\
\hline
\end{tabular}

Table 4 Polymer properties

\begin{tabular}{lll}
\hline Polymer properties & & \\
\hline Name & Zetag® 8187G & SAV 37 \\
\hline Molecular weight (MM) & $9-16$ & $2-5$ \\
Density (g/cc) & 0.7 & $0.6-0.9$ \\
\hline
\end{tabular}

sandstone rock without heterogeneity was prepared from Aghajari formation of Ahwaz Iran. Then, two sandstone cores (AS-1, AS-2) were made from this block. The petrophysical properties of cores were summarized in Table 2.

\section{Brine and formation water}

The brine $(10,000 \mathrm{ppm} \mathrm{NaCl})$ was used for flooding. The formation water $(\mathrm{FW})$ was prepared using electrolytes $\mathrm{NaCl}$, $\mathrm{KCl}, \mathrm{MgCl}_{2}$ and $\mathrm{CaCl}_{2}$ as $150,000 \mathrm{ppm}$ (TDS). Table 3 shows the concentration of each electrolyte in FW.

\section{Polymer solution}

As shown in Table 4, the co-polymer Zetag $8187 \mathrm{G}$ and SAV 37 were provided from BASF and SNF company in powder form. Polymer solutions were obtained by adding powder in brine as $2000 \mathrm{ppm}$ polymer concentration. The heater stirrer was used for preparing unique solution and increasing the temperature of solutions. The dynamic viscosity of solutions was measured using Rheometer as shown in Fig. 2.

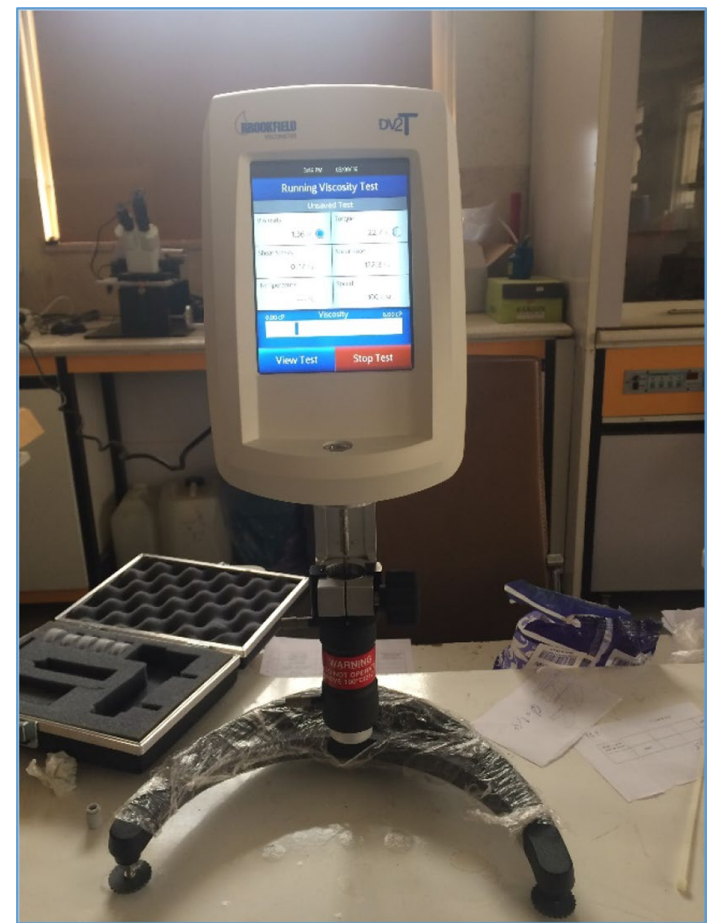

Fig. 2 Rheometer for measuring viscosity of solution

\section{Core flooding producer}

The cores were saturated with formation water using pressured cells for $72 \mathrm{~h}$ (as shown in Fig. 3). Using hand hydraulic pump, 2000 psi confining pressure was applied around the cores as confining pressure. The reduction of the pore volume after applying confining pressure was measured by measuring removal water from cores. Then the cores were kept in core-holder under $185^{\circ} \mathrm{F}$ temperature. The crude oil was injected in the core for $72 \mathrm{~h}$ to push the water and replace in pores and reach connate water saturation. When the core flooding (as sown in Fig. 4) producer reached to connate water saturation, 4 constant pressure point were considered for estimating the oil permeability. The system was kept stable at reservoir condition (2000 psi confining pressure, $150,000 \mathrm{ppm}$ formation water and $185^{\circ} \mathrm{F}$ of temperature). Then, water flooding and polymer flooding (2000 ppm polymer concentration) was applied at constant pressure 10 and $16 \mathrm{psi}$ on core AS-1 and AS-2, respectively. At the end of each flood, the relative permeability of water and polymer was measured. Additionally, water flooding was applied after polymer flooding on core AS-2 as after flush to determine formation damage in core during polymer flooding as residual resistant factor (RRF). 
Fig. 3 A schematic form of cell under pressure for core saturation



Fig. 4 A schematic of core flooding set

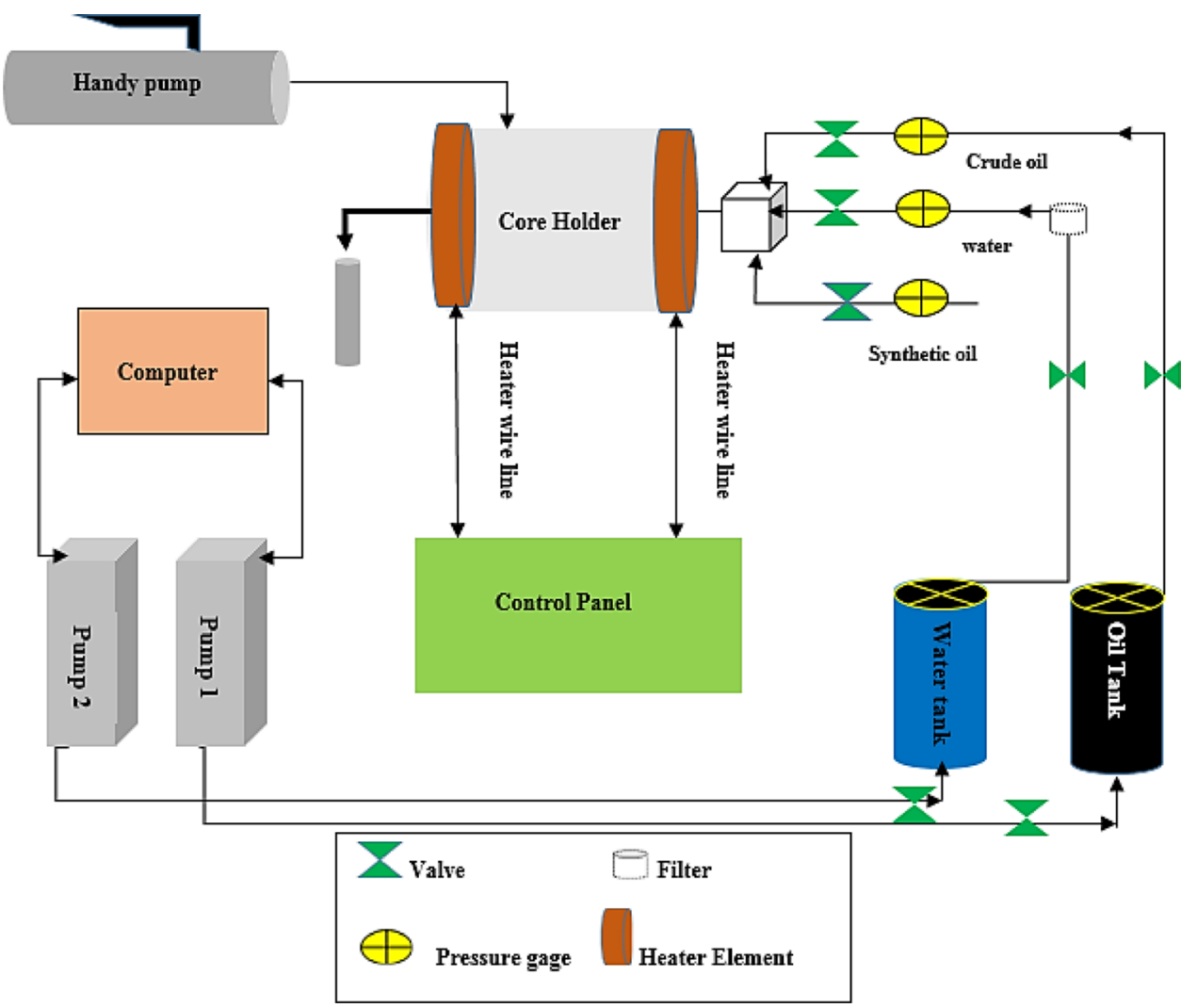

\section{Numerical simulation}

Reservoir numerical simulator is a useful tool for reservoir evaluation with low cost and saves time. In simulation, it is significant that the generated model by simulator be history matched with production data until use for predicting reservoir behavior. In the present study, one of the commercial simulators is considered for numerical simulation with the goal to
Table 5 Well constrain parameters

\begin{tabular}{lll}
\hline & Injection (psi) & Production (psi) \\
\hline BHP (psi)-water flooding & 30 & 14.7 \\
BHP (psi)-polymer flooding & 36 & 14.7 \\
\hline
\end{tabular}

obtain relative permeability curves during water and polymer flooding. A Cartesian model with bloke dimensional 20*10*1 (i, j, and $\mathrm{K}$ direction, respectively) based on core sample was 
Table 6 Initial condition values

Initial condition values

Reference pressure (psi)

2000 psi

Reference depth (cm)

$3.686 \mathrm{~cm}$

generated. The well properties and initial condition were summarized in Tables 5 and 6.

The relative permeability curves based on Corey general equation were considered for history matching by changing in the value of the power exponent for water and oil as shown in Eqs. 1 and 2:

$K_{\mathrm{ro}}=K_{\mathrm{ro} \cdot \max }\left(\frac{S_{\mathrm{o}}-S_{\mathrm{or}}}{1-S_{\mathrm{or}}-S_{\mathrm{wc}}-S_{\mathrm{gc}}}\right)^{n_{\mathrm{o}}}$

Fig. 5 Effect of the temperature on viscosity of solutions in 10,000 ppm salinity

Fig. 6 Effect of the temperature on viscosity of solutions in 150,000 ppm salinity
$K_{\mathrm{rw}}=K_{\mathrm{rw} \cdot \max }\left(\frac{S_{\mathrm{w}}-S_{\mathrm{wc}}}{1-S_{\mathrm{or}}-S_{\mathrm{wc}}-S_{\mathrm{gc}}}\right)^{n_{\mathrm{w}}}$

where $K_{\mathrm{rw}}$ is water relative permeability, $K_{\text {rw.max }}$ is water relative permeability at irreducible oil saturation, $S_{\mathrm{wc}}$ is critical water saturation, $S_{\mathrm{w}}$ is water saturation, $S_{\mathrm{or}}$ is irreducible oil saturation, $n_{\mathrm{w}}$ is exponent for calculating $K_{\mathrm{rw}}, K_{\text {ro }}$ is oil relative permeability, $K_{\text {ro,max }}$ is oil relative permeability at connate water saturation, $S_{\mathrm{o}}$ is oil saturation, $S_{\mathrm{gc}}$ is connate gas saturation, and $n_{\mathrm{o}}$ is exponent for calculating $K_{\mathrm{ro}}$.
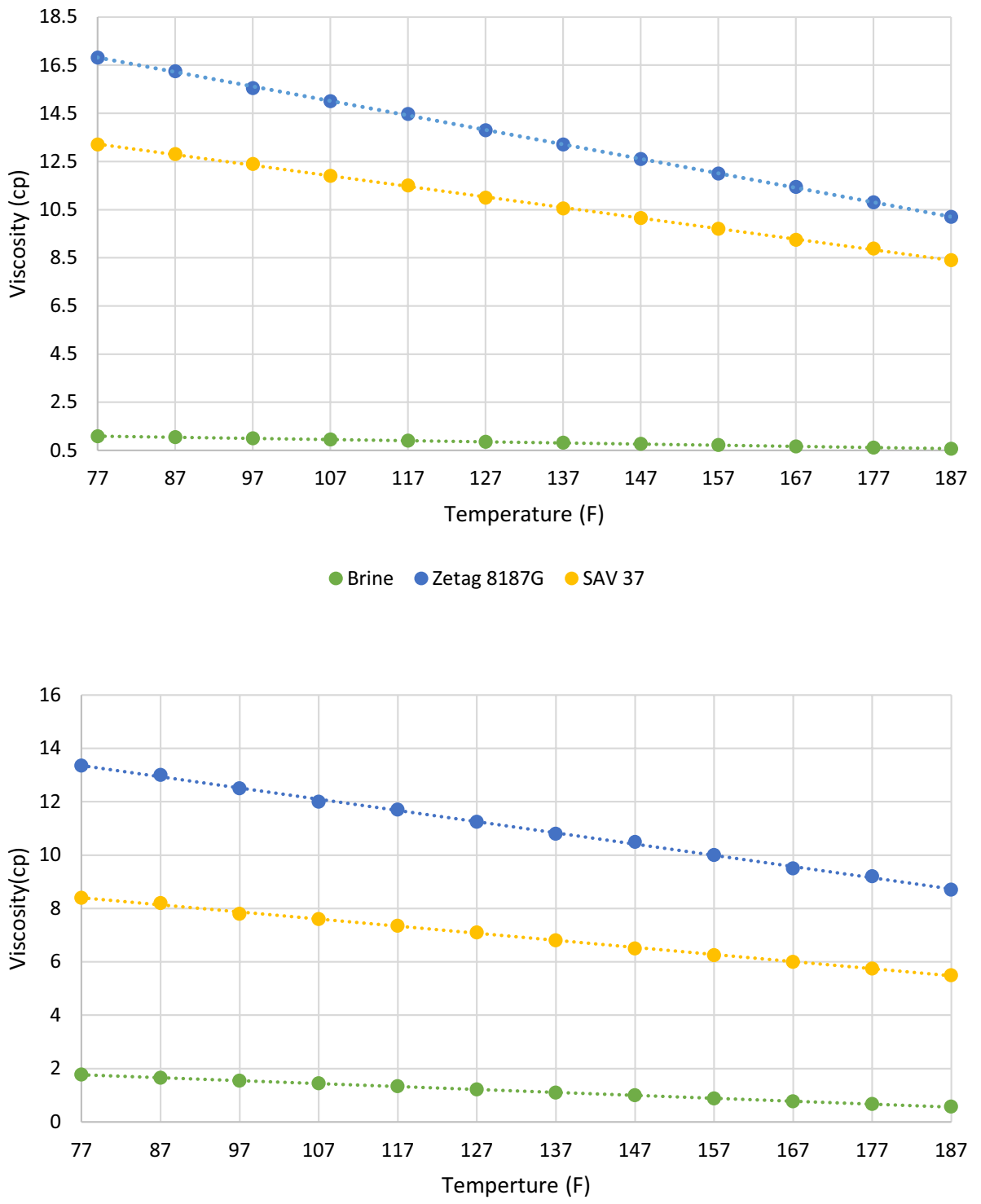

- Formation water O Zetag 8187G SAV 37 


\section{Results}

\section{Rheological behavior}

The viscosity of solutions was measured using Rheometer as dynamic viscosity. As show in Fig. 5, by increasing the temperature, the viscosity of solutions (brine, Zetag $8187 \mathrm{G}$, and SAV 37) were decreased. But, during temperature raising the Zetag $8187 \mathrm{G}$ solution was more stable than SAV 37. More than, as shown in Fig. 6, by increasing the temperature in high salinity condition (150,000 ppm formation water) the viscosity of solutions (brine, Zetag $8187 \mathrm{G}$, and SAV 37) were decreased. But in this condition Zetag $8187 \mathrm{G}$ solution had more viscosity compared to SAV 37.

For investigation the effect of salinity and presents of the divalent ions in high temperature, as shown in Fig. 7, by increasing salinity in $185^{\circ} \mathrm{F}$ the viscosity of solutions were decreased. On the other hand, viscosity change in Zetag $8187 \mathrm{G}$ was lower compared to SAV 37 . In addition, the viscosity of Zetag $8187 \mathrm{G}$ was more than SAV 37 during salinity raising.

Based on the results of viscosity behavior, Zetag $8187 \mathrm{G}$ had better stability in high temperature and high salinity condition due to low change in viscosity and greater amount compared to oil industry polymer SAV 37 that was designed for HTHS condition. Therefore, Zetag $8187 \mathrm{G}$ was considered for polymer flooding to investigation performance on residual oil and damage on rock in HTHS condition. But it is necessary to specified the thermal stability of the polymer solution by past of time, because in field condition it is important that polymer solution keeps its viscosity during injection time due to large scale of oil reservoir. Therefore, the thermal stability of Zetag $8187 \mathrm{G}$ in $150,000 \mathrm{ppm}$ TDS (present of divalent) at $185^{\circ} \mathrm{F}$ was

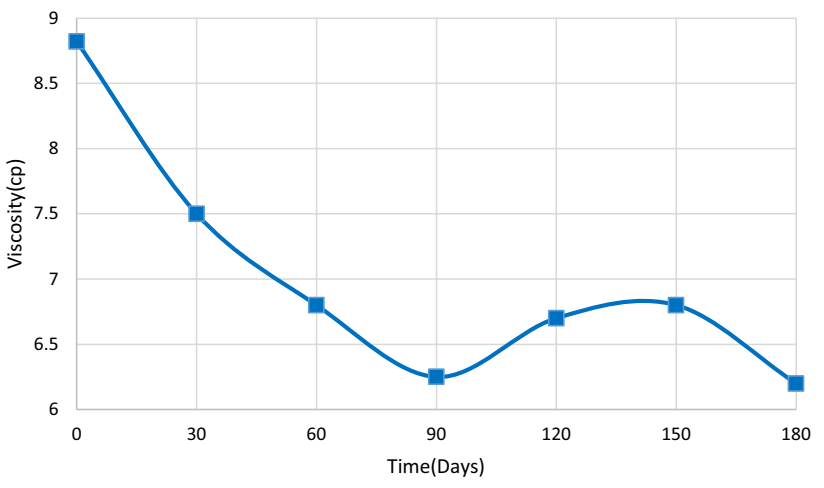

Fig. 8 long time stability of polymer solution during 180 days (polymer concentration $2000 \mathrm{ppm}$, synthetic formation water salinity $150,000 \mathrm{ppm}$, temperature $185^{\circ} \mathrm{F}$ )

measured for 180 days. As show in Fig. 8, change in viscosity of solution was not significant. It shows that solution was stable.

\section{Core flooding}

The brine as displacing fluid had $1.08 \mathrm{cp}$ viscosity at $77^{\circ} \mathrm{F}$, but when the brine reached to core holder the viscosity was decreased to $0.54 \mathrm{cp}$ due to high temperature. Therefore, water flooding results showed that breakthrough of water was occurred $8.6 \mathrm{~min}$ after of starting flood. In addition, the breakthrough was occurred after 0.16 pore volume injected. The results show mobility ratio $(M)$ of displacing fluid to displaced fluid during water flooding was more than $1(M>1)$. But in polymer flooding, the viscosity of polymer solution in brine was obtained $16.81 \mathrm{cp}$ at $77^{\circ} \mathrm{F}$. When the polymer solution reached to core holder the
Fig. 7 Effect of the salinity on solution viscosity in high temperature condition

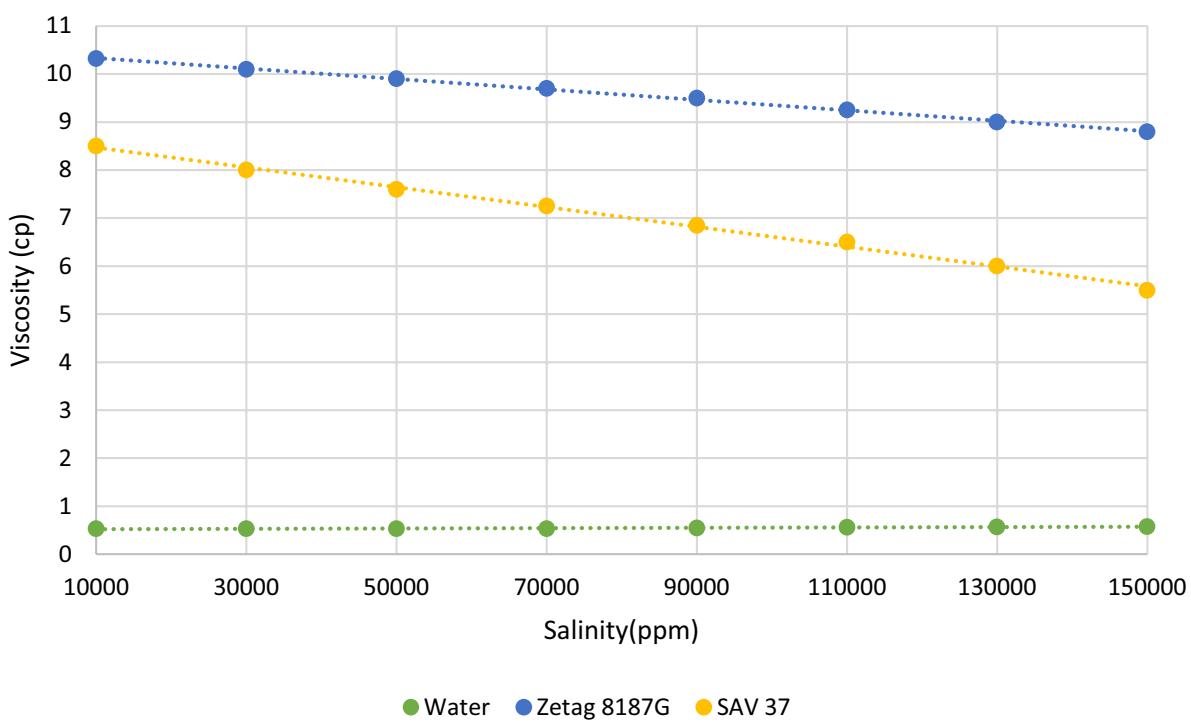




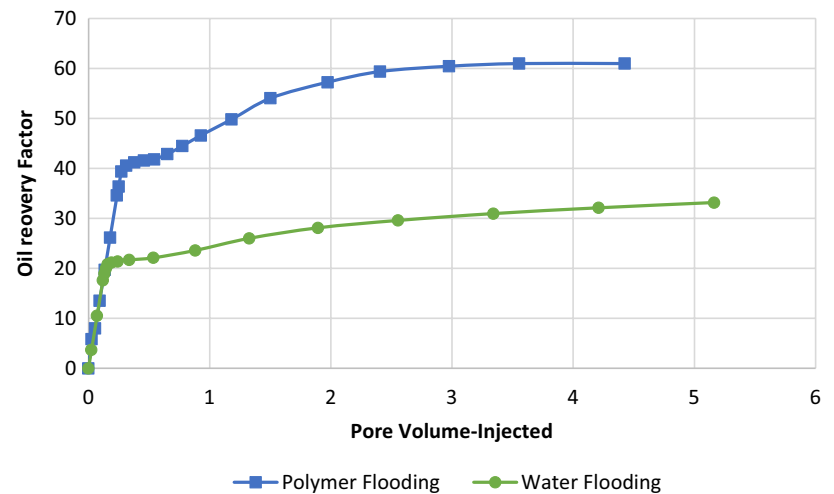

Fig. 9 Oil recovery factor for water and polymer flooding

viscosity of solution was decreased to $8.82 \mathrm{cp}$ because of high temperature and high salinity condition in the core. The results showed breakthrough during polymer flooding was occurred $13 \mathrm{~min}$ after of flooding and the 0.3 pore volume of injected. Therefore, it showed polymer solution improved the recovery of oil by prohibiting of fingering phenomena compared to water flooding. As shown in Fig. 9, the oil recovery factor after water flooding was obtained $33 \%$ but in polymer flooding it was reached to $60 \%$. More than, after 1 pore volume injected (PV-INJ) the oil recovery factor was obtained approximately $50 \%$. It shows this polymer has good performance in porous media at HTHS condition and it have economically consideration. As shown in Fig. 10, the residual oil saturation after polymer flooding was lower compared to water flooding. This results show polymer flooding using Zetag $8187 \mathrm{G}$ was successful due

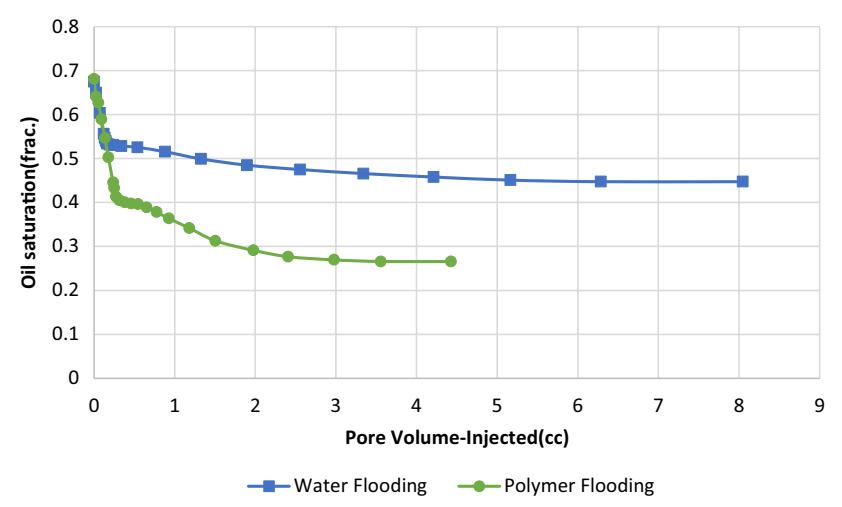

Fig. 10 Residual oil saturation for water and polymer flooding to low residual oil saturation in porous media and high value of oil recovery factor. The summarization of flooding results are presented in Table 7.

Additionally, during polymer flood there are two main factor: resistant factor (RF) and residual resistant factor (RRF). The resistance factor is a term that is usually used to show the resistance to flow in porous media by a polymer solution as compared to the flow of water (Lyons 2009). This factor is defined as:

$\mathrm{RF}=\frac{\left(\frac{K}{\mu}\right) \text { water flooding }}{\left(\frac{K}{\mu}\right) \text { polymer flooding }}=\frac{\Delta P \text { polymer }}{\Delta P \text { water }}$

The core flooding results showed, the resistant factor (RF) during polymer flooding was 5.01. This means polymer flooding using Zetag $8187 \mathrm{G}$ was five times harder compared to water. Based on what was reported about polymer flooding, this value is acceptable due to high molecular weight.

Another phenomenon related to polymer is the reduction in effective permeability of displacing fluid after the polymer flooding which is known as residual resistance factor (RRF). The RRF is the ratio of mobility of initial injected water to the mobility of injected water behind the polymer solution (Cannella et al. 1988). This factor is defined as:

$$
\begin{aligned}
\mathrm{RRF} & =\frac{\left(\frac{K}{\mu}\right) \text { before polymer flooding }}{\left(\frac{K}{\mu}\right) \text { after polymer flooding }} \\
& =\frac{\Delta P \text { water after polymer flooding }}{\Delta P \text { water before polymer flooding }}
\end{aligned}
$$

Based on the after flush and pre flush data, RRF was estimated 1.39. This means permeability of core after polymer flooding was reduced to $13 \mathrm{mD}$. The permeability reduction $5 \mathrm{mD}$ during polymer flooding in HTHS condition is very excellent. There are two main reasons for this damage; first, the sand stone core contains clay mineral with negative charge that caused to polymer molecule adsorbed on rock surface. Second, hydrolyzed of acrylamide in high temperature, tends it to polymer trapping by divalent ions. Therefore, combination of clay mineral and HTHS condition did not main effect on rock damage during polymer flooding using Zetag $8187 \mathrm{G}$.
Table 7 The summarizations of the core flooding results

\begin{tabular}{lllllll}
\hline & $S_{\mathrm{iw}}(\%)$ & $S_{\mathrm{o}}(\%)$ & $T_{\mathrm{bt}}(\min )$ & $\mathrm{PV}_{\mathrm{bt}}$ & $\mathrm{RF}(\%)$ & $S_{\text {or }}(\%)$ \\
\hline Water flooding & 32 & 68 & 8 & 0.16 & 33.68 & 44.72 \\
Polymer flooding & 31.9 & 68.1 & 13 & 0.3 & 60.95 & 26.58 \\
\hline
\end{tabular}




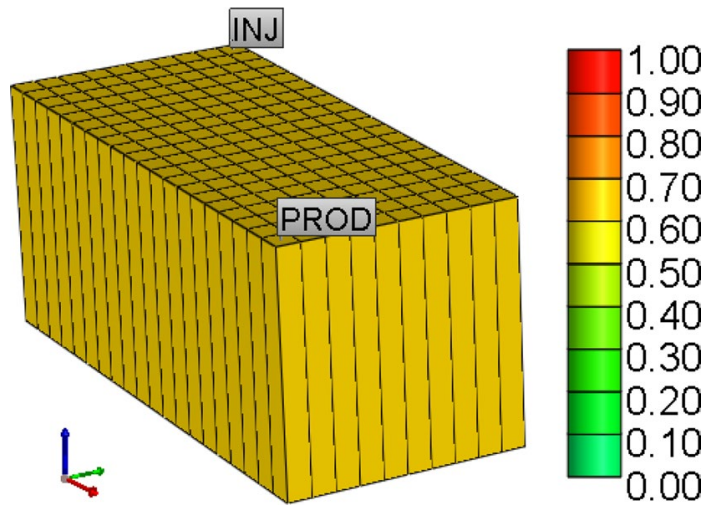

Fig. 11 Core sample 3D model. The color legend shows the initial oil saturation

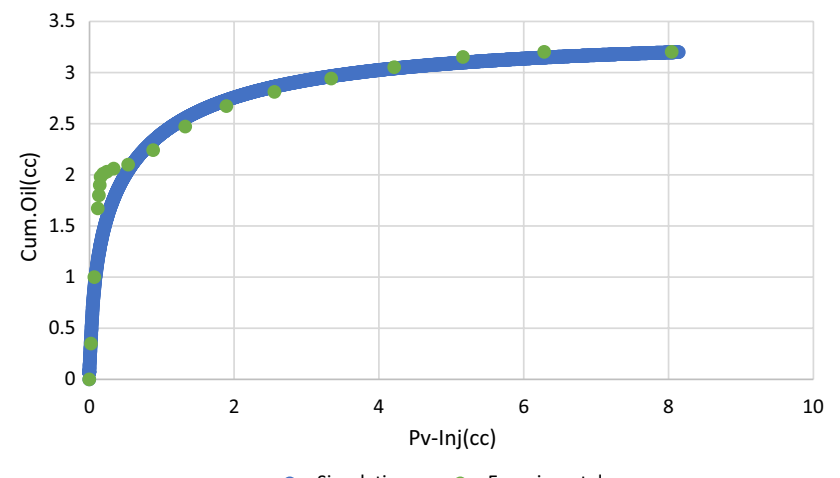

Fig. 12 History matching of cumulative oil production in water flooding

Fig. 13 History matching of oil saturation during water flooding

\section{Numerical simulation}

As shown in Fig. 11a Cartesian model was considered as a reservoir based on the core sample properties. As shown in the Figs. 12, 13, 14, 15, the history matching of production data was obtained during water and polymer flooding by changing the value of power exponent in Corey correlation. The $\mathrm{n}$-exponent for water and oil relative permeability for water flooding was estimated 1.3 and 1.7. But in polymer flooding, the n-exponent for water and oil relative permeability was estimated 2.5 and 1.8. Relative permeability values and end-points saturation for water flooding and polymer flooding from experimental results are summarized in Table 8. As shown in Fig. 16, comparison of the relative permeability curves shows that oil relative permeability curve in polymer flooding was shifted to the right and it shows polymer flooding was improved the flooding efficiency. On the other hand, the water relative permeability curve in polymer flooding has lower slope compared to water flooding. This behavior shows the effect of mobility control of polymer solution. As shown in Figs. 17 and 18, the simulation results show mobility ratio $(M)$ of displacing fluid to displaced fluid during water flooding was more than polymer flooding. This fact shows the mobility control of displacing fluid by adding polymer. More than, the intersect point of water and oil relative permeability curves in polymer flooding was shifted to right. It shows this co-polymer have surfactant rule in addition to the polymeric rule.

\section{Conclusion}

The main object of this study was to investigate the performance of new co-polymer (Zetag 8187G) for polymer flooding in high temperature and high salinity condition.

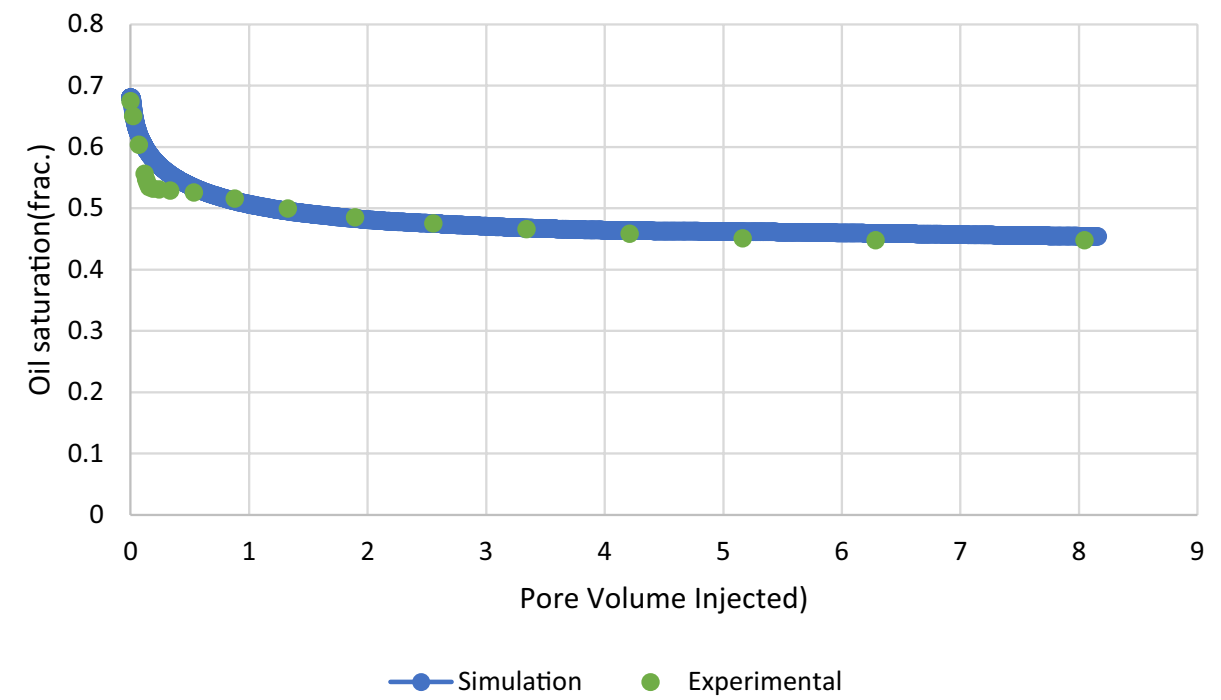




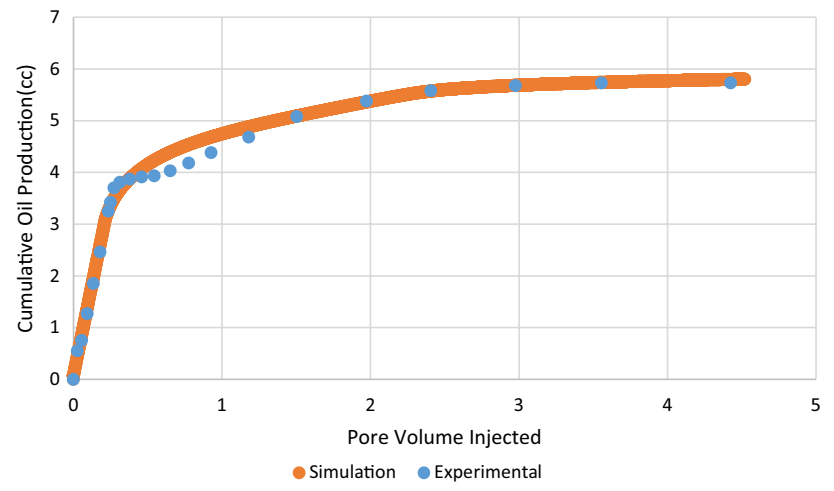

Fig. 14 History matching of cumulative oil production during polymer flooding

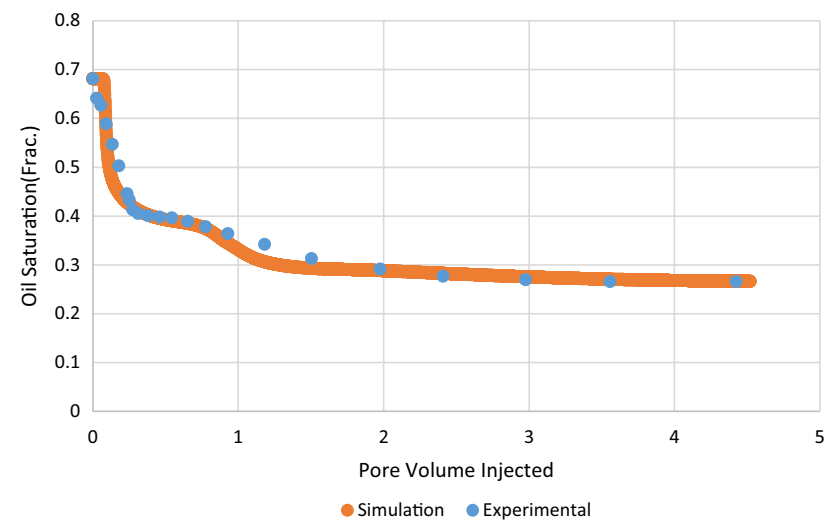

Fig. 15 History matching of oil saturation during polymer flooding

Table 8 Relative permeability in end-point saturation of water (up) and polymer (down) flooding

\begin{tabular}{lll}
\hline Phase & End-point saturation & Relative permeability \\
\hline Water & $S_{\mathrm{wc}}=32 \%$ & $K_{\mathrm{o}}=0.3$ \\
Oil & $S_{\mathrm{or}}=44.73 \%$ & $K_{\mathrm{w}}=0.1$ \\
Water & $S_{\mathrm{wc}}=31.9 \%$ & $K_{\mathrm{o}}=0.3$ \\
Oil & $S_{\mathrm{or}}=26.5 \%$ & $K_{\mathrm{p}}=0.056$ \\
\hline
\end{tabular}

This polymer was not used in oil industry, but it was used in water industry as flocculant. The rheological behavior of the polymers shows that by increasing temperature and salinity the viscosity of polymers solution was decreased but Zetag $8187 \mathrm{G}$ was more stable compared to SAV 37 . The water flooding in HTHS condition recovered $33.68 \%$ of initial oil in place (IOIP), but on the other hand, polymer flooding using Zetag $8187 \mathrm{G}$ recovered $60.95 \%$ of IOIP. It shows Co-polymer Zetag $8187 \mathrm{G}$ was applicable for HTHS condition due to $27.27 \%$ increasing oil recovery. Additionally, the

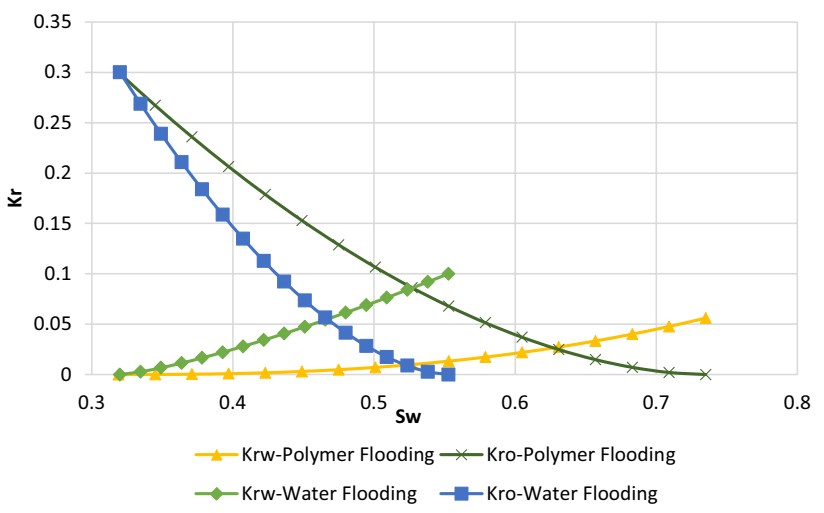

Fig. 16 Comparison of relative permeability curve for water and polymer flooding

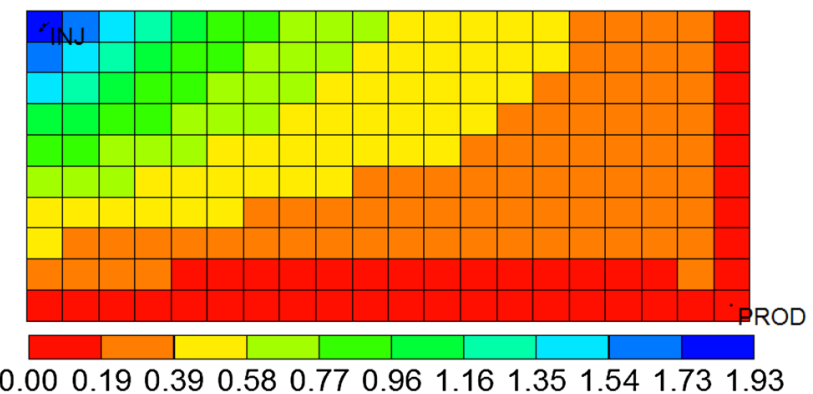

Fig. 17 Water phase mobility during water flooding $(M>1)$

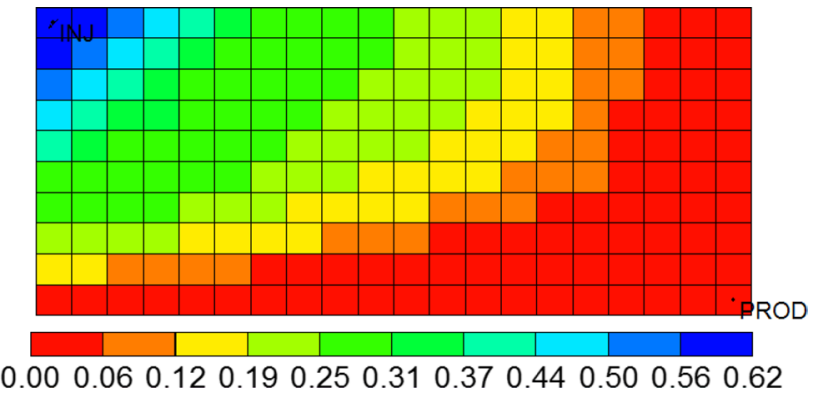

Fig. 18 Water phase mobility during polymer flooding $(M<1)$

resistant factor (RF) and residual resistant factor (RRF) of this polymer was estimated 5.01 and 1.39 , respectively. The RF defined polymer flooding using Zetag $8187 \mathrm{G}$ was 5.01 harder compared to water flooding. In addition, the RRF illustrated the rock permeability was decreased to $13 \mathrm{mD}$ compared to initial value $(18 \mathrm{mD})$. It clarified rock damage during polymer flooding was not significant. Finally, according to rheological study and core flooding, Zetag $8187 \mathrm{G}$ can be a good choice for polymer flooding in HTHS oil reservoir. 
Open Access This article is distributed under the terms of the Creative Commons Attribution 4.0 International License (http://creativeco mmons.org/licenses/by/4.0/), which permits unrestricted use, distribution, and reproduction in any medium, provided you give appropriate credit to the original author(s) and the source, provide a link to the Creative Commons license, and indicate if changes were made.

\section{References}

Abidin AZ, Puspasari T, Nugroho WA (2012) Polymers for enhanced oil recovery technology. Proc Chem 4:11-16

Alvarado V, Manrique E (2010) Enhanced oil recovery: an update review. Energies, 3:1529-1575

Cannella W, Huh C, Seright R (1988) Prediction of xanthan rheology in porous media. In: SPE annual technical conference and exhibition

Han M, AlSofi A, Fuseni A, Zhou X, Hassan S (2013) Development of chemical EOR formulations for a high temperature and high salinity carbonate reservoir. In: IPTC 2013: international petroleum technology conference

Hashmet MR, AlSumaiti AM, Qaiser Y, AlAmeri WS (2017) Laboratory investigation and simulation modeling of polymer flooding in high-temperature. High-Salinity Carbonate Reservoirs. Energy Fuels 31:13454-13465

Jiang Z, Zhu J (2014) Cationic polyacrylamide: synthesis and application in sludge dewatering treatment: a review. Asian J Chem 26:629

Kamal MS, Sultan AS, Al-Mubaiyedh UA, Hussein IA (2015) Review on polymer flooding: rheology, adsorption, stability, and field applications of various polymer systems. Polym Rev 55:491-530

Lyons W (2009) Working guide to reservoir engineering. gulf professional publishing, Houston

Lyons WC, Plisga GJ (2011) Standard handbook of petroleum and natural gas engineering. Elsevier, Amsterdam

Pope GA (1980) The application of fractional flow theory to enhanced oil recovery. Soc Petrol Eng J 20:191-205
Quadri SMR, Jiran L, Shoaib M, Hashmet MR, AlSumaiti AM, Alhassan SM (2015) Application of biopolymer to improve oil recovery in high temperature high salinity carbonate reservoirs. In: Abu Dhabi international petroleum exhibition and conference

Sandrea I, Sandrea R (2007) Global oil reserves-1: recovery factors leave vast target for EOR technologies. Oil Gas J 105:44,

Sarsenbekuly B, Kang W, Fan H, Yang H, Dai C, Zhao B et al (2017) Study of salt tolerance and temperature resistance of a hydrophobically modified polyacrylamide based novel functional polymer for EOR. Colloids Surf A 514:91-97

Vermolen E, Van Haasterecht MJ, Masalmeh SK, Faber MJ, Boersma DM, Gruenenfelder MA (2011) Pushing the envelope for polymer flooding towards high-temperature and high-salinity reservoirs with polyacrylamide based ter-polymers. In: SPE middle east oil and gas show and conference

Wang W, Liu Y, Gu Y (2003) Application of a novel polymer system in chemical enhanced oil recovery (EOR). Colloid Polym Sci 281:1046-1054

Wang Y, Lu ZY, Han YG, Feng YJ, Tang CL (2011) A novel thermoviscosifying water-soluble polymer for enhancing oil recovery from high-temperature and high-salinity oil reservoirs Adv Mater Res 306:654-657

Wang G, Yi X, Feng X, Jing B, Ouyang J (2012) Synthesis and study of a new copolymer for polymer flooding in high-temperature, high-salinity reservoirs. Chem Technol Fuels Oils 48:112-119

Wu Y, Mahmoudkhani A, Watson P, Fenderson TR, Nair M (2012) Development of new polymers with better performance under conditions of high temperature and high salinity. In: SPE EOR conference at oil and gas West Asia

Zhu D, Wei L, Wang B, Feng Y (2014) Aqueous hybrids of silica nanoparticles and hydrophobically associating hydrolyzed polyacrylamide used for EOR in high-temperature and high-salinity reservoirs. Energies 7:3858-3871,

Publisher's Note Springer Nature remains neutral with regard to jurisdictional claims in published maps and institutional affiliations. 